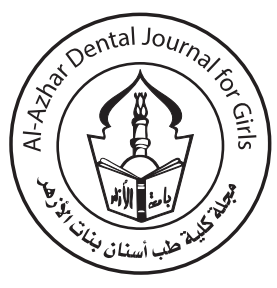

\title{
Evaluation of Antibacterial Effect of Rosmarinus Officinalis Extract on Streptococcus Mutans in Children
}

\author{
Mai I. Okasha ${ }^{1 *}$, Mohammed H. Mostafa ${ }^{2}$, Salam M. El-Araby ${ }^{3}$
}

Codex : 18/22.01

azhardentj@azhar.edu.eg

http://adjg.journals.ekb.eg

DOI: $10.21608 /$ adjg.2021.29662.1259

Pediatric Dentistry \& Orthodontics ( Pediatric Dentistry, Orthodontics)

\section{KEYWORDS}

Rosemary,

Chlorhexidine, Caries.

\begin{abstract}
Purpose The aim of study was to evaluate antibacterial effect of Rosemarinus officinalis extract on Streptococcus Mutans in group of Egyptian children in comparison with gold standard chlorhexidine. Subjects and Methods: Total of 40 Egyptian children with no sex predilection included in this study. Children's ages ranged from 6 to 12 years. Children divided into 2 groups A and B. Group A (experimental group): 20 children instructed to rinse with $5 \mathrm{ml}$ of $\mathrm{R}$. officinalis extract twice per day for 2 weeks 30 seconds/rinse. Group B (control group): 20 children instructed to rinse with $5 \mathrm{ml}$ of Chlorhexidine $(0.12 \%)$ twice per day for 2 weeks 30 seconds/rinse. Results: In both groups there was statistically significant reduction in Streptococcus Mutans counts were obtained but the reduction was found slightly higher in chlorhexidine group. Conclusions: The use of Rosmarinus officinalis extract in children is safer than chlorhexidine because rosemary is natural herb that does not contain any chemicals.
\end{abstract}

\section{INTRODUCTION}

Dental caries is the most prevalent disease of humans which results from cycles of demineralization and remineralization, and depends on lifestyle ${ }^{(1)}$.

Dental caries is characteristically cumulative and becomes complex by time, caused by Streptococcus Mutans bacteria ${ }^{(1)}$. Pain caused by caries can affect children's concentration in schools and thus their quality of life $\mathrm{e}^{(2)}$.

* Paper extracted from Master thesis titled "Evaluation of Antibacterial Effect of Rosmarinus Officinalis Extract on Streptococcus Mutans in children "

1. Postgraduate student at Pedodontics and Oral Health Department, Faculty of Dental Medicine for Girls, Al-Azhar University, Cairo, Egypt .

2. Assistant Professor and Head of Pedodontics and Oral Health Department, Faculty of Dental Medicine for Girls, Al-Azhar University, Cairo, Egypt.

3. Lecturer of Pedodontics and Oral Health Department, Faculty of Dental Medicine for Girls, Al-Azhar University, Cairo, Egypt.

* Corresponding author email: mai.okasha1986@gmail.com 
Mouthwashes are a commonly used tool used to achieve therapeutic intervention to all surfaces of the mouth, including interproximal surfaces. These mouthwashes are able to prevent bacterial adhesion, colonization of bacteria and its metabolic activity which affect the growth of bacteria. Mouthwashes eliminate the need for manual interventional procedures and the timing of the procedure can also be regulated ${ }^{(3)}$.

Phytotherapy in pediatric dentistry considers medicinal plants safer than conventional treatments and chemical medicaments and have fewer adverse effects thus, the tendency to use medicinal plants for children has increased ${ }^{(4)}$.

Rosmarinus officinalis plant (R. oficinalis) is from the Lamiaceae family, also called the mint family, the rosemary extract has antibacterial, antioxidative and antifungal properties ${ }^{(5)}$. It was found that the hydroalcoholic extract of R. officinalis showed effectiveness against oral plankton bacteria like Streptococcus Mutans, involved in oral biofilm formation. The field of phytotherapy using medicinal plants is vast, and involves many purposes, including use in the oral healthcare profession ${ }^{(6)}$.

\section{MATERIALS AND METHODS}

Materials used in the study: Rosmarinus officinalis extract made from rosemary leaves (Commercially available as a product of American Garden Company, New York, U.S.A), used as mouthwash placed in hermetically sealed bottles and kept at the refrigerator, chlorhexidine mouthwash (Hexitol, $0.125 \%$; Adco, Cairo, Egypt) was used in this study, Mitis Salivarius Bacitracin (MSB): plate supplied with sucrose to selectively isolate oral streptococci and inhibit any other micro-organisms (Fig.1).

Case Selection: Ethical approval was obtained from the Research and Ethics committee of the Faculty of Dental Medicine of Al-Azhar University (Girl's branch), Cairo - Egypt, the study was explained to all the participants' guardians, and they signed informed consent denoting their agreement

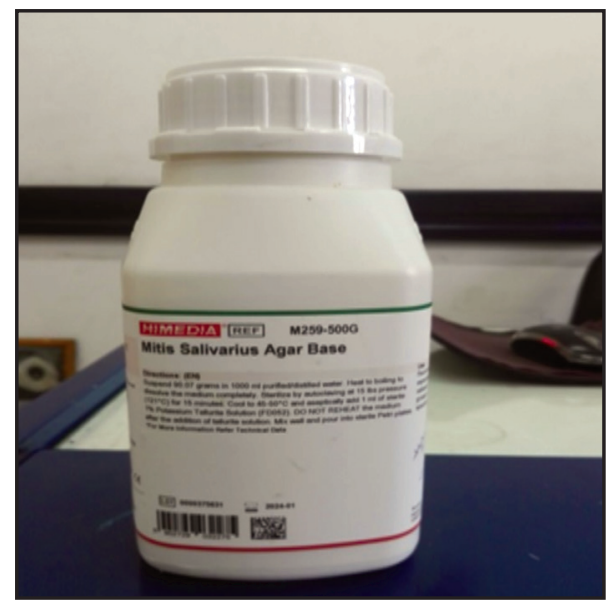

Figure (1) Mitis Salivarius Bacitracin Agar Base.

to participate in the study. Also, verbal consent from the children has been obtained. The children were selected from orphanages in Nasr City and Maadi, their ages ranging from (6 to 12) years.

\section{Inclusion Criteria $^{(7)}$ :}

- Children's ages were between 6 and 12 years old, and they were in physically good health.

- No history of wearing fixed or removable orthodontic appliance or removable prosthesis.

- $\quad$ Mixed dentition age.

- Decayed-Missing-Filled (DMF) and (def) $>4$ (high caries index), high caries risk assessment was done using Caries-risk Assessment Tool $(\mathrm{CAT})^{(8)}$

\section{Exclusion Criteria $^{(7)}$ :}

- Children with oral or systemic diseases.

- History of recent administration of antibiotic (previous 2 weeks).

- History of recent antimicrobial mouthwash use (previous 12 hours).

- History of recent treatment with fluoride in the past 2 weeks. 


\section{Methods:}

A total of 40 Egyptian children were randomly divided into two groups $\mathrm{A}$ and $\mathrm{B}$, with twenty children in each group. Group A (Experimental group) Twenty children, children were instructed to rinse with $5 \mathrm{ml}$ of $\mathrm{R}$. officinalis extract twice per day for two weeks with an average of thirty seconds/ rinse. Group B (control group) Twenty children, children were instructed to rinse with $5 \mathrm{ml}$ of Chlorhexidine mouthwash $(0.12 \%)$ (Hexitol) twice per day for two weeks with an average of thirty seconds / rinse. Preparation of aqueous extract of rosemary: For the laboratory scale extraction, 400 $\mathrm{g}$ of dried chopped leaves of rosemary was added to $1200 \mathrm{~mL}$ of distilled water at $80^{\circ} \mathrm{C}$ with manual agitation. When reached $60-65^{\circ} \mathrm{C}$, the mixture was homogenized with ultraturrax at 20,000 rpm and the aqueous extract was acquired by maceration for 30 minutes with separation of insoluble solids by centrifugation $^{(9)}$.

Collection of saliva samples: Non-stimulated saliva samples were collected from the participants by asking them to spit in a labeled sterile container $(2 \mathrm{ml} \text { on average })^{(10)}$.

Initial sample $\left(\mathbf{S}_{1}\right)$ : The initial samples were taken before using the mouthwash by asking the children to spit in a labeled sterile container ${ }^{(10)}$.

Second sample $\left(\mathbf{S}_{2}\right)$ : The second samples were taken thirty minutes after the children rinsed with specific amounts of the mouthwash $(5 \mathrm{ml})^{(11)}$.
Third sample $\left(\mathbf{S}_{3}\right)$ : The final samples were taken after the completion of the mouthwash in two weeks ${ }^{(10,12)}$. Microbiological analysis: saliva samples were processed immediately in Culture and Sensitivity Unit at Regional center for Mycology and Biotechnology at ALAzhar University to assess the S. mutans level. The saliva samples were diluted in $0.05 \mathrm{M}$ phosphate buffer $(\mathrm{pH} 7.0)$ to the serial dilutions of $1 / 10^{3}$ by using micropipette, samples were agitated for 30 seconds on a vortex mixer.

One milliliter of saliva sample was incorporated into Mitis Salivarius Bacitracin Agar (MSB) using pour plate method. The agar plates were incubated at $37^{\circ} \mathrm{C}$ for 48 hours under $10 \% \mathrm{CO}_{2}$ anaerobic conditions ${ }^{(13)}$, colonies of S. mutans were identified as round or spherical, convex, raised, and dark blue irregular colonies ${ }^{(14)}$.

\section{RESULTS}

In thirty minutes and two weeks post treatment with Rosemary and Chlorhexidine groups, it was recorded that there was a marked decrease in the percentage of colony forming units of Streptococcus Mutans. In Rosemary group, the count decreased by $(98.07 \pm 3.44 \%)$ after 30 minutes and by $(99.9981 \pm 0.0017 \%)$ after two weeks. In Chlorhexidine group, the colony count decreased by $(99.98 \pm 0.02 \%)$ after thirty minutes and by $(99.9996 \pm 0.003 \%)$ after two weeks as shown in table 1 and fig.2(). Mann - Whitney test revealed that the difference in percent decrease in CFU of Streptococcus Mutans between both groups was statistically significant in favor for Chlorhexidine ( $\mathrm{p}$ value $<0.001$ ).

Table (1): Comparison of mean percent change in colony forming unit of Streptococcus Mutans (\%) in Rosemary and Chlorhexidine groups after treatment.

\begin{tabular}{|c|c|c|c|c|c|c|c|c|c|c|c|}
\hline \multirow{2}{*}{$\begin{array}{c}\text { Colony } \\
\text { forming unit of } \\
\text { Streptococcus } \\
\text { Mutans }\end{array}$} & \multicolumn{5}{|c|}{ Rosmarinus officinalis extract group } & \multicolumn{5}{|c|}{ Chlorohexidine group } & \multirow{2}{*}{ P value } \\
\hline & Mean & SD & Median & Minimum & Maximum & Mean & SD & Median & Minimum & Maximum & \\
\hline $\begin{array}{c}\% \text { change } \\
\text { after } 30 \mathrm{~min}\end{array}$ & -98.07 & 3.44 & -99.69 & -99.99 & -82.50 & -99.98 & 0.02 & -99.99 & -99.99 & -99.96 & $<0.001$ \\
\hline $\begin{array}{l}\% \text { change after } \\
\text { two weeks }\end{array}$ & -99.9981 & 0.0017 & -99.9986 & -99.9999 & -99.9937 & -99.9996 & 0.0003 & -99.9998 & -100.0000 & -99.9992 & $<0.001$ \\
\hline
\end{tabular}

* P-values less than 0.05 considered as statistically significant. 


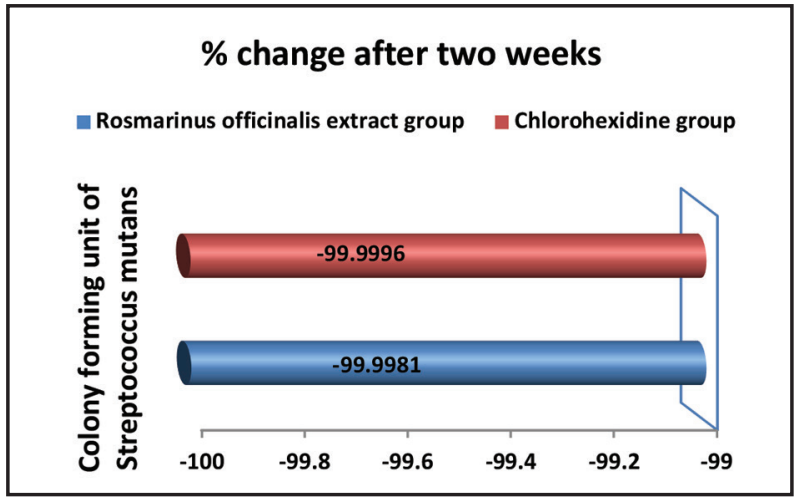

Figure (2) Bar chart showing mean percent change in colony forming units of $\mathrm{S}$. mutans(\%) in Rosemary and chlorhexidine groups after two weeks of treatment.

\section{DISCUSSION}

Dental caries is a main concern in dental practice that results from chemical dissolution of the tooth surface caused by the production of acid by the acidogenic bacteria in dental plaque biofilm which results from continuous exposure to different types of sugars. The main pathological factor of dental caries is related to the activity of Streptococcus Mutans based on microbiological analysis. Dental caries is always preceded by the presence of dental plaque biofilm $^{(15)}$.

Chlorhexidine mouthwash is used in oral preventive therapy due to its broad-spectrum antimicrobial activity. Common side effects of chlorhexidine include: tooth and tongue discoloration, metallic taste, irritation and laceration of mouth and tongue, unpleasant taste and decreased taste sensation ${ }^{(16)}$.

Studies emphasized on the antimicrobial activity of R. officinalis, enabling to use the rosemary plant in many pharmaceutical aspects. It was emphasized on its great results as a mouthwash prepared from the aqueous extract of rosemary in this current study. The Rosemary mouthwash was prepared from the aqueous extract of $\mathrm{R}$. officinalis. The mouthwash was made in an aqueous extract method to eliminate the unwanted adverse effects of the alcoholic extraction method, especially in children.

Alcohol is an ingredient that is primarily available in a number of products that are accessible to children. Ingestion of these alcohol-containing products can lead to significant health risks ${ }^{(17)}$. There are many reported cases of ethanol intoxication, poisoning, or death in children, so that's why it was preferred to use an aqueous extract rather than an alcoholic extract, especially ethanol extract ${ }^{(18)}$.

In the current study the age group of children was chosen from 6 to 12years old because they can swish and spit after rinsing and they don't sallow the mouthwash so the product can be used with efficiency and safety ${ }^{(10)}$. Another reason for choosing this age group is that the high infectivity of $\mathrm{S}$. mutans occurs in the mixed dentition period (6-12 years) ${ }^{(19)}$.

In vitro the minimal inhibitory concentration MIC of aqueous R. officinalis extract in this current study was $15.63(\mu \mathrm{g} / \mathrm{ml})$ which equal $1.563 \%$. In agreement with this current study another study showed near MIC result, the assessment of the antimicrobial activates of $R$. officinalis against $S$. mutans showed that the MIC of R. officinalis extract against $\mathrm{S}$. mutans was $4 \mathrm{mg} / \mathrm{ml}^{(20)}$.

\section{CONCLUSION}

Both Rosemary and Chlorhexidine have antibacterial activities similar to each other but due to the side effects of chlorhexidine it is preferable to use rosemary extract mouth wash especially in children to avoid the side effects of chlorhexidine.

\section{CONFLICT OF INTEREST}

None declared.

\section{FUNDING}

No funding was received for this study. 


\section{REFERENCES}

1. Somaraj V, Rekha R, Shenoy G, Kumar V, Jodalli $\mathrm{P}$, Sonde L, et al. Effect of herbal and fluoride mouth rinses on Streptococcus Mutans and dental caries among 12-15-Year-old school children: a randomized controlled trial. In J Dent. 2017; 2:1-8.

2. Gilchrist F, Marshman Z, Deery C, Rodd H. The impact of dental caries on children and young people. Int J Paediatr Dent. 2015;25:327-38.

3. Takenaka S, Ohsumi T. Evidence-based strategy for dental biofilms: Current evidence of mouthwashes on dental biofilm and gingivitis. Jpn Dent Sci Rev. 2019;55:33-40.

4. Salman B, Vahabi S, Rad M. Use of herbs and medicinal plants in dentistry: A review. J Dent Sch. 2017; 35:133-49.

5. Nieto G, Ros G, Castillo J. Antioxidant and antimicrobial properties of Rosemary (Rosmarinus officinalis, L.): A review. Medicines. 2018;5: 1-13.

6. Valones M, Higino J, Souza P, Crovella S. Dentifrice containing extract of Rosmarinus officinalis Linn.: An antimicrobial evaluation. Braz Dent J. 2016;27:497-501.

7. Goyal A, Bhat M, Sharma M, Garg M, Khairwa A, Garg R. Effect of green tea mouth rinse on Streptococcus Mutans in plaque and saliva in children:An in vivo study. J Indain Soc Pedod Prev Dent. 2017;35;41-6.

8. American Academy of Pediatric Dentistry. Guideline on caries-risk assessment and management for infants, children, and adolescents. Pediatr Dent. 2016; 38:142-9.

9. Bestagno V, Neira I, Gómez-Gaete P, Pastene E, Gómez M. Oral study of the effect of Rosmarinus officinalis (Rosemary) mouthrinse on healing wounds of the oral Mucosa. Int J Odontostomat. 2017;11:411-17.

10. Moness A, Ahmed W, Abdel-baky R, Amer M. Antibacterial efficacy of green tea mouth rinse in children with early childhood caries. Tanta Dent J. 2019; 16:6-11.

11. Palit M, Hedge S, Bhat S, Vij C, Trivedi D, Setty S, et al . Effectiveness of mouthrinse formulated from aqueous extract of Terminalia Chebula on salivary Streptococcus Mutans count and ph among 8- to 12-year-old school children of Karnataka: A randomized clinical trial. Int J Clin Pediatr Dent. 2016;9:349-54.

12. Mahyari S, Mahyari B. Evaluation of the efficacy of a polyherbal mouthwash containing Zingiber officinale, Rosmarinus officinalis and Calendula officinalis extracts in patients with gingivitis: A randomized double-blind placebo-controlled trial. Complement Ther Clin Pract. 2016; 22: $93-8$.

13. Lee Y, Kim M, Kim J. Detection of Streptococcus Mutans in human saliva and plaque using selective media, polymerase chain reaction, and monoclonal antibodies. Oral Biol Res. 2019;43:121-9.

14. Manju M , Prathyusha P . Evaluation of the effect of three supplementary oral hygiene measures on salivary mutans streptococci levels in children: A randomized comparative clinical trial. Eur J Dent. 2015; 9: 462-69.

15. Sheiham A, James W. Diet and dental caries:The pivotal role of free sugars reemphasized. J Dent Res. 2015; 94:1341-7.

16. Jassoma E, Baeesa L, Sabbagh H. The antiplaque/anticariogenic efficacy of Salvadora persica (Miswak) mouthrinse in comparison to that of chlorhexidine: A systematic review and meta-analysis. BMC Oral Health. 2019; 19: 64-8.

17. Hertzog J, Radwick A. Acute alcohol intoxication in a child following ingestion of an ethyl-alcohol-based hand sanitizer. Int J Clin Pharmacol Ther. 2015;53:557-6.

18. Santos C, Kieszak S, Wang A, Law R, Schier J. Reported adverse health effects in children from ingestion of alcohol-based hand sanitizers. MMWR. 2017;66:223-26.

19. Shah S, Bargale S, Dave H, Deshpande A, Kariya P. Comparison of antimicrobial efficacy of (between) $0.2 \%$ Chlorhexidine and herbal mouthwash on salivary Streptococcus Mutans: A randomized controlled pilot study. Contemp Clin Dent. 2018; 9: 440-45.

20. Shekar B, Nagarajappa R, Suma S, Thakur R . Herbal extracts in oral health care: A review of the current scenario and its future needs. Pharmacogn Rev. 2015; 9:87-92. 